el Inventario de Nuevas Adquisiciones del Museo del Prado, y el número 5597 en el Catálogo de este mismo Museo ${ }^{12}$.

Nosotros identificamos este cuadro del Museo del Prado denominado Últimos mártires del cristianismo con el presentado a la Exposición Nacional de Bellas Artes de 1884 bajo el título de Eudoro y Cymodocea en el anfiteatro, extraído del citado pasaje de Los Mártires de Chateaubriand, no sólo gracias a la descripción del asunto del mismo que nos proporciona el texto literario reproducido en el Catálogo de la Exposición Nacional de 1884 antes citado, que coincide plenamente con el tema del cuadro depositado por el Museo del Prado en el Ayuntamiento de Mataró (Barcelona), sino también porque las dimensiones prácticamente son las mismas: 2,90 × 4,08 ms. en el Catálogo de la Exposición Nacional de $1884^{13}$, y 2,90 × 4,03 ms. en el Inventario de «El Prado disperso», publicado en el Boletín del Museo del Prado ${ }^{14} ; \mathrm{y}$, además, la fecha de ejecución del depositado en Mataró, 1884, coincide con la de la Exposición Nacional de 1884. Con lo que claramente se trata del mismo cuadro.

El cambio de título pensamos que fuese debido quizá a la dificultad que, en su día, representaba el ponerle el complejo y culto título - por añadidura en francés- que originariamente llevaba el cuadro, que, incluso traducido, poco o nada diría a un público en general mayoritariamente de escasa cultura literaria y, más aún, siendo extranjera, como en este caso.

De todas formas, y a pesar de la poca fama de que debió gozar en vida Bermudo Mateos, no creemos que fuese tan mal pintor como para merecer los satíricos versos que dedicaron Granés y Vallejo a su cuadro de Una bacante. Válganos como compensación el hecho de que, en dicho Catálogo cómico-crítico de la Exposición Nacional de 1876, pocos son los artistas que salen bien parados de los mordaces y jocosos comentarios de dichos autores. El cuadro que tratamos de Eudoro y Cymododocea en el anfiteatro, no es una gran obra, pero tampoco es mala. Y, de hecho, aunque no fuese premiado ni nos conste que tuviese ninguna mención honorífica en la Exposición Nacional de 1884, fue sin embargo adquirido por el Estado. Hay buenas cosas en esta obra, como el estudio arqueológico realizado por el autor en las vestimentas de los personajes y el tratamiento de los paños al estilo clásico, así como la representación de las figuras y de las fieras, que tampoco son malas. Hay, eso sí, falta de fuerza, cierta blandenguería en las actitudes y en la composición del grupo principal. Es, en definitiva, un cuadro «pompier» como tantos muchos de los que por esas fechas se hicieron en Francia y otros países de Europa.

ENRIQUe ARIAS ANGLÉS

CSIC

Aurora Gil Serrano

Instituto Antonio López (Tres Cantos. Madrid)

\title{
UN COBRE DE WILLEM VAN HERP CON EL SUEÑO DEL PATRICIO JUAN $Y$ SU ESPOSA DEL TEMPLO DE LA VIRGEN DE LAS NIEVES
}

En visita de los fondos fotográficos del Museo Nacional de San Carlos de Méjico vi, sin catalogación o propuesta alguna en cuanto al autor y asunto representado, este cobre que restituimos a Willem van Herp, de notables proporciones, como es frecuente en su producción [Fig. 1]. Es comprensible que ofrezca dificultades por lo escaso y singular del tema en la ico-

12 «El 'Prado disperso'», Boletín del Museo del Prado, t. XII, núm. 30, Madrid, 1991, p. 127, núm. 5597.

13 Op. cit., nota 9, p. 23.

14 Op. cit., nota 12. 


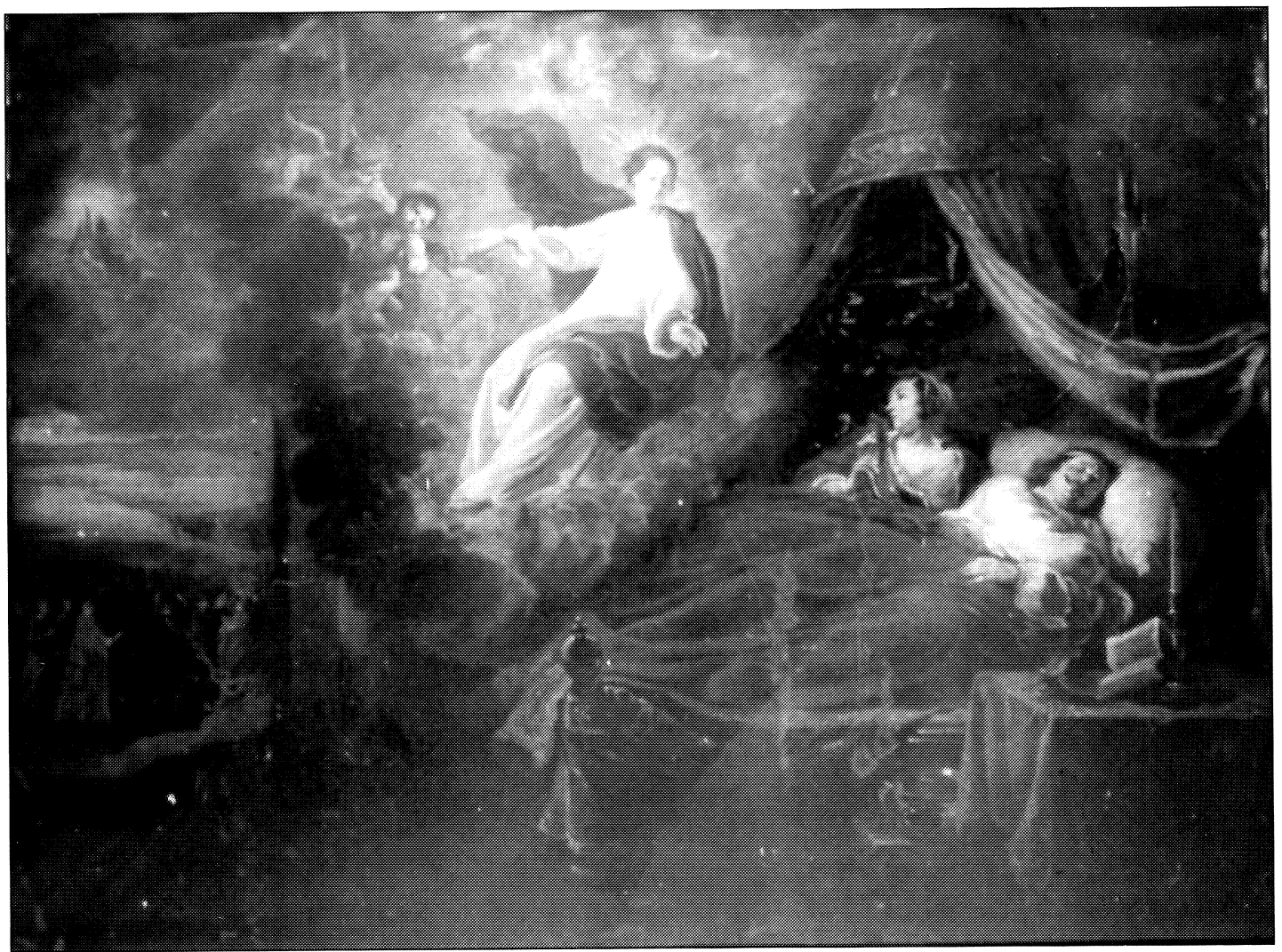

1

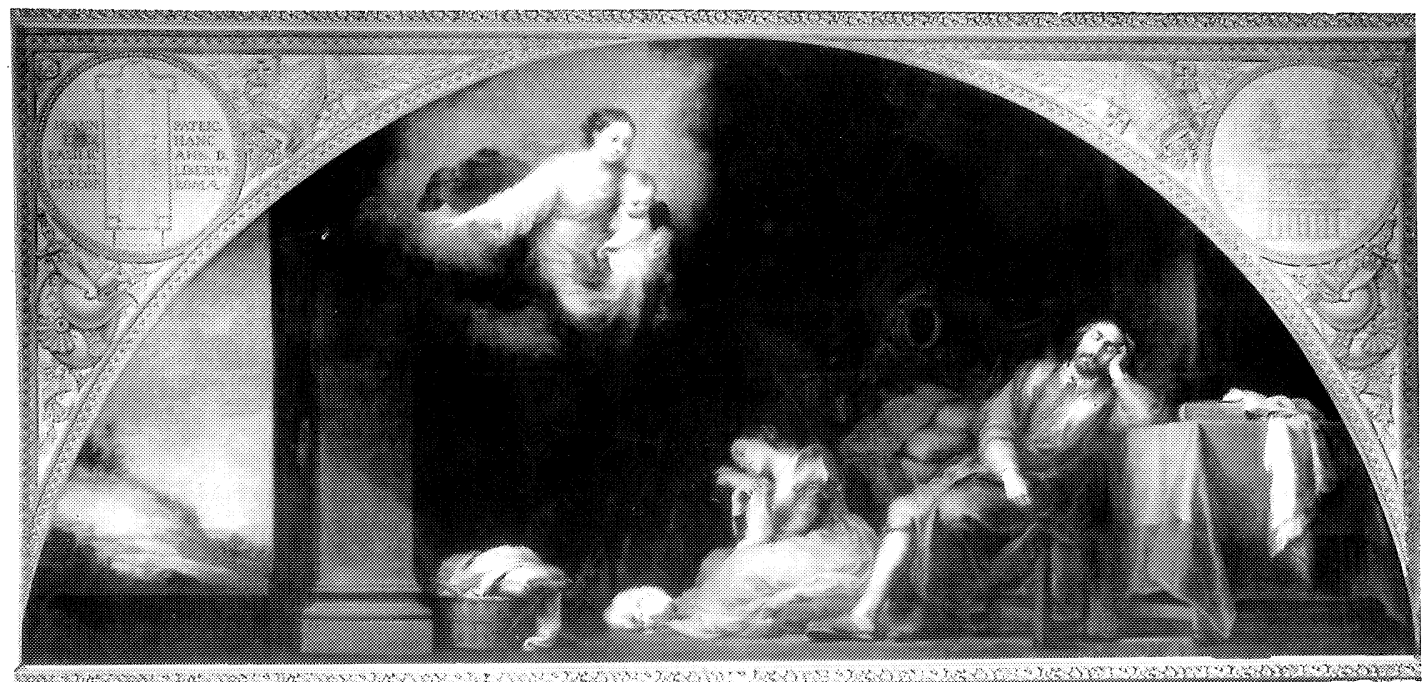

Fig. 1. W. van Herp: El sueño del patricio. Méjico, colección privada.

Fig. 2. Murillo: El sueño del patricio. Museo del Prado.

AEA, LXXVI, 2003, 301, pp. 79 a 93 
nografía cristiana. Pero no es difícil para quienes visitamos las salas consagradas a Murillo en el Museo del Prado. Esta asociación entre este pintor flamenco y nuestro maestro sevillano dejaría de sorprender si se probara la existencia de lazos ocultos en el espacio y en el tiempo. A la altura del conocimiento de la vida y obra de Williem van Herp, esta coincidencia puede tener sentido. De una parte, la obra de Willem van Herp no se limita a su Amberes natal y a Inglaterra, donde tuvo una merecida acogida en el s. XVIII ' ${ }^{1}$. Hay pruebas suficientes que lo vinculan de manera insospechada con España. Las obras localizadas por Enrique Valdivieso en Andalucía y por quien esto escribe en Castilla lo confirma ${ }^{2}$. Al margen de las obras conocidas, son muchas las localizadas en envíos a través del puerto de Amberes a Cádiz, Málaga y Sevilla $^{3}$. Su obra no llega a España por la vía noble de la Corte, sino por la Iglesia y el pueblo devoto ${ }^{4}$. Es en este ámbito donde localizamos la mayor parte de sus pinturas, fundamentalmente en cobre, soporte más idóneo para la exportación por su inalterabilidad al medio ambiente.

La historia del Patricio Juan y su mujer fue reverenciada al fundar el templo de la Virgen de las Nieves en Sevilla, encargándose a Murillo dos grandes lienzos con la leyenda de sus fundadores [Fig.; 2-3 $]^{5}$. No extraña que un acontecimiento tan relevante tuviera repercusión en los Países Bajos, y se encargaran desde aquí cobres con este asunto a un pintor nórdico con estimable clientela en Sevilla. Tampoco es extraño que estos cobres pasen a Nueva España, a través de los puertos citados, para las iglesias y conventos del otro lado del Imperio ${ }^{6}$. El cobre que estudiamos es de interés, no sólo por su identificación, sino por testimoniar compromisos con la clientela devota de España, y con Murillo, en la ruta hacia el Nuevo Mundo por aquélla España sin límites. De aquí que el radio de expansión de sus obras en vida vaya más allá del continente europeo, como hemos visto en Hendrik van Balen, Pierre van Lint y Victor Wolfoert ${ }^{7}$.

La composición de Van Herp coincide con el lienzo de Murillo [Fig. 2] en la distribución de las masas, movimiento de las formas e intencionalidad sacral. Sólo existen diferencias de tono menor que especificaremos. Quienes conocemos el estilo de Willem van Herp, reconocemos con facilidad en este cobre sus juegos efectistas de diagonales y perspectivas, y sus modelos distinguidos y alargados, de un manierismo retardado con excepción de la imagen socarrona del prócer romano durmiendo en el lecho. Los modelos son reconocibles en el rostro de la esposa recostada, la Virgen y los serafines. La factura es sólida, con trazos vivos de su especial manera de tratar las manos, rostros y objetos. La precisión de la pincelada es impecable.

\footnotetext{
${ }^{1}$ Legrand, F.C., Les peintres flamands de genre au Xvilème siècle, Paris-Bruselas, 1963, p. 167, nota 302.

2 Valdivieso, E., «Obras inéditas de Willem van Herp», Boletín del Seminario de Estudios de Arte y Arqueología, Universidad de Valladolid, 1973, p. 487; Idem, «Obras de Guillaume van Herp en España I y II», Archivo Español de Arte, T. L y LI, n. 200 y 201, Madrid, 1977, p. 365, 1978, No. 201, p. 10; Idem, «Nuevas pinturas de Guillaume van Herp», Miscelánea de Arte, Madrid, 1982; Idem, «Nuevas pinturas de satélites de Rubens inéditas o mal atribuidas en colecciones españolas y extranjeras: Van Lint, Van Herp, Bosschaert y Van Balen», Archivo Español de Arte, n. 241, Madrid, 1988.'

3 Denucé, J., Na Peter Pauwel Rubens. Dokumenten in kunsthandel te Antwerpen in de 17de eeuw van Matthijs Músson, Antwerpen, 1949. Gregory Martin piensa que El milagro de San Antonio de Padua de la National Gallery de Londres sea el enviado a Cádiz [National Gallery Catalogue. The Flemish School, 1600-1900, Londres, 1970, p. 83.], pero podría tratarse de los ejemplares existentes en El Henar y Catedral de Segovia [Sanzsalazar, J., La obra de Willem van Herp, Mémoire de Maîtrise, Université Panthéon-Sorbonne, París, 1999, t. I, p. 66].

${ }^{4}$ Es oportuno advertir que los cobres del Museo del Prado que hemos estudiado no tienen el mismo origen del resto de las obras de las Colecciones Reales. [Díaz Padrón, M., Catálogo de Pinturas del Museo del Prado. Escuela flamenca del siglo XVH, vol. I, Madrid, 1975, p. 157].

5 Angulo Iñigụez, D., Murillo. Catálogo críticb, Madrid, 1981,.I, p., 324

${ }^{6}$ Es sobradamente conocida la existencia de cobres de pintores similares a Willem van Herp encontrados en Sudamérica.

7 Obregón, G., «El aporte flamenco en Méjico», Artes de Méjico, No. 150, 1972, pp. 67-92 (sin precisar los pintores); Díaz Padrón, M., «La obra de Pierre van Lint en España», Goya, No. 145, 1978, p. 17; Idem, «Hendricke van Balen, pintor de Cámara de la archiduquesa Isabel Clara Eugenia y maestro de Van Dyck, en las Islas Canarias», Coloquio Internacional 1580-1648, IV centenario del ataque de Van der Does a Las Palmas de Gran Canaria, Las Palmas, 1999, pp. 695717; Idem, «Dos cobres de Victor Wolvoet en el Museo de San Carlos de Méjico», Boletín del Seminario de Estudios de Arte y Arqueología de la Universidad de Valladolid, 1999, LXV, p. 323.
} 
Las luces subyugan por sus efectos vibrantes y espontáneos: imaginables en otros artistas del entorno. Este diseño asume por igual los ritmos de los personajes y los objetos más peregrinos del escenario. La mesa, el libro abierto, el candelabro y bacinilla se captan con igual materialidad física. La luz imprime un potencial sorprendente en esta pintura, como es común en otras donde aparece un hecho milagroso. Algo de estos contrastes tenebristas debe a Jacob Jordaens, aunque el diseño de las manos y gestos de la Virgen haya que buscarlo en Rubens, a quien copia en tantas ocasiones ${ }^{8}$. El rostro de la Virgen se repite en la Diana de Caza de la colección Namur, en Hipómenes y Atalanta del Museo Nacional de Varsovia, Nacimiento de la Virgen de colección madrileña, Anunciación de colección privada de Méjico, Bautismo de San Agustín de los Agustinos de Amberes y Alegre Compañía de la colección Wemyss.

Es una historia devota la que narra Willem van Herp, pero es evidente que los ojos ven una escena de jugosa cotidianeidad del vivir doméstico en una alcoba burguesa. Esto se produce igual en el lienzo de El sueño del Patricio y su esposa de Murillo del Museo del Prado. Pero la interpretación del pintor flamenco acentúa la imagen cotidiana, dispone a los esposos en un lecho con la riqueza de un noble prócer, pero la situación no deja de ser vulgar en el mejor sentido. La luz incide sobre los esposos; es una luz onírica que transmite el cuerpo glorioso de la Virgen. El resto del escenario queda en penumbra para destacar el protagonismo de la pareja. En el lado izquierdo, en la lejanía, se divisa una multitud fundida en la atmósfera, con gracia y animada devoción, con un minucioso tratamiento del que hace gala el pintor en tantas otras composiciones, utilizando escenas historiadas de la secuencia principal.

Es una de las pinturas más vivaces y espontáneas que conozco en su producción, donde la libertad de su inspiración se manifiesta sin reservas. A estas apreciaciones anímicas, añadimos el alto grado de calidad conseguido. Afecta a su conservación alguna zona de saltados en la capa de color a lo ancho del lecho y ángulo izquierdo del cobre.

Estamos tentados de pensar que este cobre fue producto del clima fundacional de Santa María la Blanca, entre 1665 y 1668, cuando Murillo pinta los lienzos de la historia de los devotos mecenas en Sevilla, donde -como hemos dicho anteriormente- Willem van Herp gozaba de cierta clientela. Pensamos que podría fecharse después de 1668 hasta la muerte del pintor en 1677.

La iglesia sevillana se remodeló con boato y lujo y gran repercusión en la cristiandad. No sólo fue un acontecimiento en Sevilla, sino un fasto glorioso en la Historia del Arte, como escribe Diego Angulo según las crónicas del momento ${ }^{9}$. No es extraño que el eco de este acontecimiento tuviera repercusión en el norte de Europa. Murillo trató el asunto con el mismo aire profano, casi como una pintura de género. También es oportuno recordar en este juego de dependencias con el ambiente español que el viejo templo de Santa María la Mayor de Roma, que reproduce en su interior el mismo asunto, estaba bajo la protección de la Corona española. Este templo no escapa a los vínculos con el Nuevo Mundo, pues el techo fue dorado con el oro que Colón trajo de América y donó el Rey Católico al Pontífice. Más tarde, en vida de Willem van Herp, se levantó en el pórtico de la iglesia romana la estatua de Felipe IV según Bernini.

La leyenda tiene lugar en el pontificado de Liberio, en el siglo IV, cuando el noble romano llamado Juan y su esposa desearon dar testimonio de fervor a la Virgen, haciéndola heredera de sus bienes. La Virgen aparece en sueños por separado a los dos, el cinco de agosto del año 352 , revelándoles su deseo de fundar una iglesia en honor suyo y de su hijo, en la cima del

\footnotetext{
8 Puyvelde, L. van, «Guillaume van Herp, Bon peintre et copiste de Rubens», Zeitschrift für Kunstgeschichte, XXII, 1959, pp. 46-48.

9 Angulo Iñiguez, D., Op. Cit. 1981, I, p. 321.

AEA, LXXVI, 2003, 301, pp. 79 a 93
} 


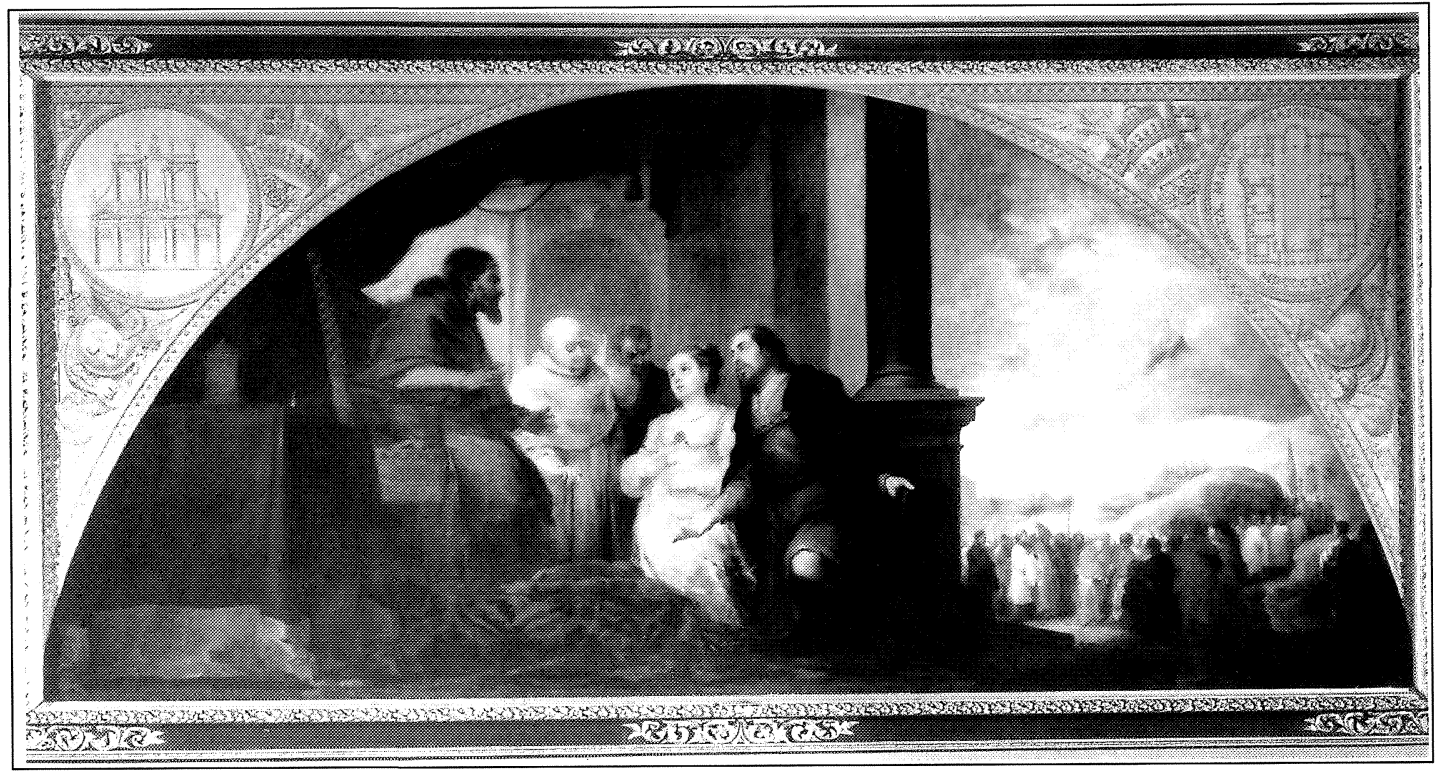

3

4
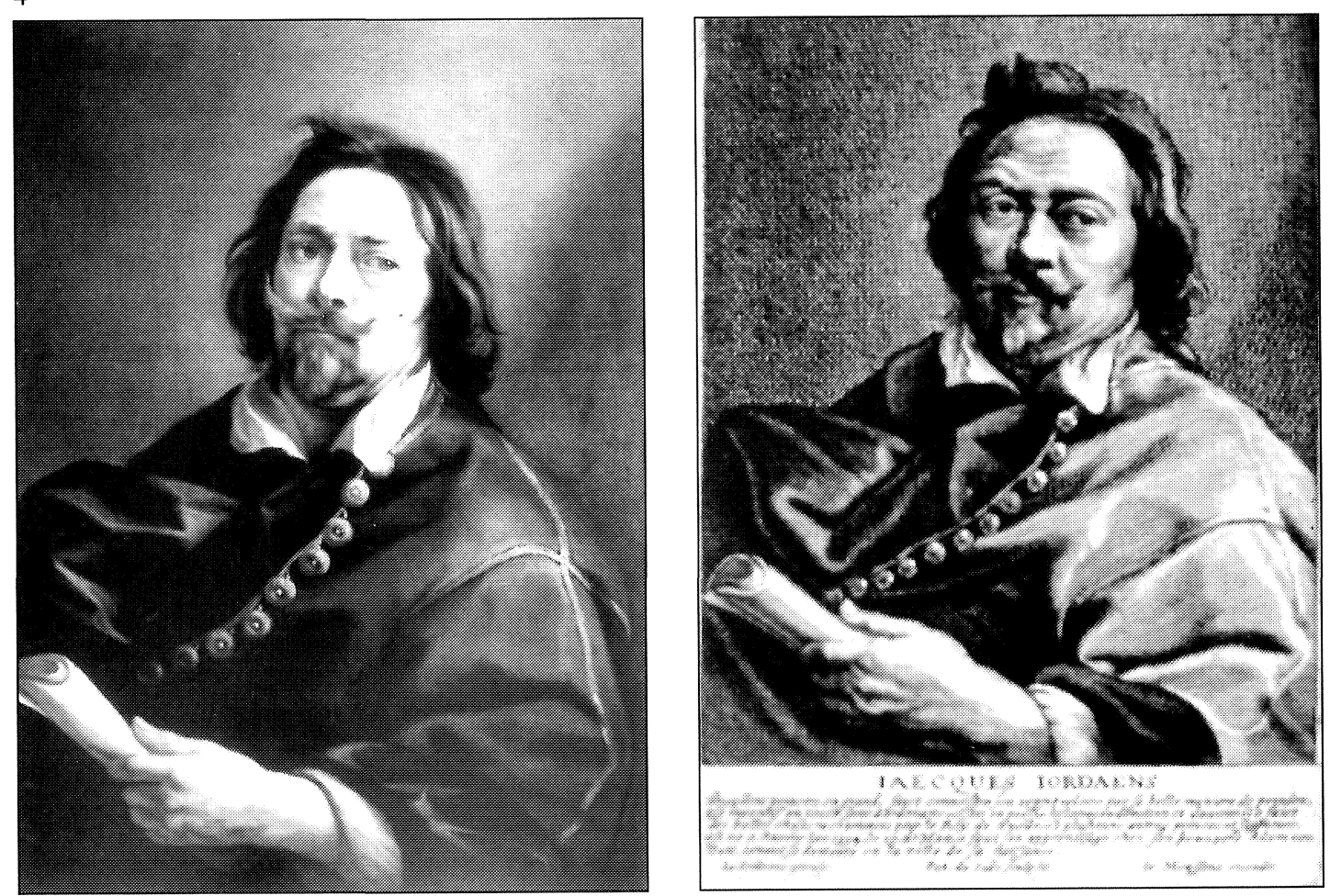

Fig. 3. Murillo: El patricio Juan y su esposa ante el presbiterio. Museo del Prado.

Fig. 4. Jordaens. Amsterdam. Colección privada.

Fig. 5. Pieter de Jode y J. Meyssens. Según Jordaens.

AEA, LXXVI, 2003, 301, pp. 79 a 93 
monte Esquilino, y les presenta el plano del templo dibujado con nieve ${ }^{10}$. El Papa tuvo el mismo sueño y organizó una expedición al monte para comprobar el milagro. Es la procesión a la izquierda del cobre, en perspectiva aérea. La nieve cubre el espacio consagrado al futuro templo, a pesar de estar en verano. En el lienzo de Murillo aparece el Niño en brazos de la Virgen, pero en el cobre figura sola, pero aparece con el Niño en una secuencia posterior, en la lejanía del cielo, fundida entre las nubes, amparando a la multitud. Recordamos que en la iglesia madre, en Santa María la Mayor de Roma, se reproduce un mosaico de 1300 con la misma historia del sueño del patricio y fundación de la iglesia. La Virgen esta sola y señala desde lo alto el lugar de la edificación, igual que en el cobre. Murillo lo hace con el Niño en los brazos y los esposos durmiendo entre cojines. Es una licencia más estética la del pintor sevillano, pues las fuentes antiguas los sitúan en la cama.

Murillo representa a la esposa dormida, mientras que en el mosaico medieval - como en el cobre - está sentada y velando el sueño de su esposo. También es'un escenario suntuoso el del mosaico. Todo esto coincide con el cobre del pintor flamenco. Advertimos que la aparición de la Virgen con el Niño a los esposos, contrariamente al mosaico y al cobre- aparece en el texto del Padre Croisset. Esta debió ser la fuente directa de Murillo. No sería extraño que existiera un grabado que sirviera a ambos maestros por igual. A pesar de la presencia o ausencia del Niño en brazos de la Virgen, el esquema compositivo está trazado con igual sintonía.

Es de interés recordar que el sueño es un motivo escaso en la pintura religiosa. Murillo representa al patricio con laxitud, elegante abandono del cuerpo, y rostro bello y apacible; mientras que Willem van Herp utiliza un personaje más directo y realista, en una instantánea algo procaz, aunque sin llegar a la vulgaridad. Resulta simpático este rostro en sombra contrastada. A título de sugerencia, nos recuerda, por sus mejillas llenas y mostachos apuntados hacia arriba, a la fisonomía de Jacob Jordaens en autorretratos de sus últimos años, como el que procede de la colección del barón G. Th. A. M. van Brienen de Grootelindt en Amsterdam [Fig. 4] ${ }^{11}$, grabado por Pieter de Jode y y J. Meyssens [Fig. 5] ${ }^{12}$.

Matías DíAz PAdrón

\section{UN PRIMER RETABLO DE ALBERTO DE CHURRIGUERA}

Es conocida en lo esencial la actividad desarrollada por Alberto de Churriguera en Salamanca durante su etapa de madurez, como maestro de la Catedral y de la Plaza Mayor y al frente de las obras de los Colegios de Cuenca, de San Bartolomé o del Rey entre otros, así como diversos trabajos en Valladolid, Madrid, Orgaz y otros lugares '. Sin embargo, son muy escasas las noti-

\footnotetext{
10 «Como la visión se había hecho a los dos, no dudaron que fuere legítima y sobrenatual. No obstante, se la comunicaron al Papa Liberio, el cual había tenido otra en todo semejante la misma noche; y viendo que el cielo se explicaba, quiso el Pontífice verificar el hecho con sus propios ojos. Mandó juntar el clero, y acompannado el Patricio Juan de su mujer y de todo el piadoso pueblo, fue procesionalmente al sitio donde se había anunciado la maravilla. Llegaron al monte esquilino, y en él se halló un espacio todo cubierto de nieve, sin embargo de ser en la fuerza del estío y en el mayor rigor de los calores» [Croisset, Año cristiano]. Vid. Angulo, Op. Cit. 1981, I, pp. 326-327.

$"$ Vendida en Christie's Londres, 8-XII-1961, No. 177.

12 Hollstein, F.W.H., Eaux-fortes, estampes et gravures hollandaises et flamandes, 1450-1700, Amsterdam, $1949,24$.

' García Bellido, Antonio, «Estudios del Barroco español. Avance para una monografía de los Churriguera», en Archivo Español de Arte y Arqueología, T. V (1929), pp. 70-73 y «Estudios del Barroco español. Avance para una monografía de
}

AEA, LXXVI, 2003, 301, pp. 79 a 93 